\title{
Understanding divergence of living standards between Asia and Europe: a proposition of regionally dominant cultural effects
}

Enn Lun Yong(D)

Correspondence:

ennlunyong@gmail.com

Mathematics with Economics Program, Faculty of Science and Natural Resources, Universiti Malaysia Sabah, UMS Street, 88400 Kota Kinabalu, Sabah, Malaysia

\begin{abstract}
This paper aims to compare living standards in Asia and in Europe with respect to several cultural dimensions to which the research on economic prosperity has paid attention. Some studies pool countries in multiple regions to identify cultural effects on economic prosperity, and this paper argues that such regional differences in culture must be considered. In addition to empirically distinguishing Asia and Europe in terms of living standards with respect to selected cultural dimensions, this study also distinguishes and investigates regions within Europe. A theoretical argument explains each region's dominant cultural dimension, thereby hypothesizing regionally distinct effects of culture on living standards. A quadruple model is developed, and different samples are used to test the reliability and validity of the theoretical proposition. Two cultural dimensions, individualism and power distance, are identified as hallmarks of the divergence of living standards between Asia and Europe. Individualism has a significantly positive effect in Europe but insignificant in Asia, whereas the findings are opposite for power distance. The results remain robust even after controlling for confounders. The findings suggest potential barriers to maximizing the effectiveness of economic policies because a development approach adopted from Europe could be less effective in Asia, and vice versa, owing to a different dominant culture.
\end{abstract}

Keywords: Asia, Cultural dimension, Economic divergence, Europe, Modern economic growth, Standard of living, Western Europe

\section{Introduction}

How do geographical regions of countries affect their living standards? Despite the influences of ever-widening gaps in trade, human development, and technological progress on income inequalities across regions, this paper argues that regional differences in real living standards are rooted deeply in some heritage factors. The implication of this hypothesis is economically huge, as Mann and Riley (2007) also show evidence of lesser intra-regional income inequalities than those of inter-regional income in the past few decades (1950-2000).

The realization of income inequality, an economic egalitarian outcome, has been studied from two perspectives, namely, economic development and heritage. This

(c) The Author(s). 2019 Open Access This article is distributed under the terms of the Creative Commons Attribution 4.0 International License (http://creativecommons.org/licenses/by/4.0/), which permits unrestricted use, distribution, and reproduction in any medium, provided you give appropriate credit to the original author(s) and the source, provide a link to the Creative Commons license, and indicate if changes were made. 
categorization is based on Rodrik's (2003) taxonomy of determinants of economic growth, namely geography, institution, and integration. Income per capita, likewise one popular indicator of living standards in macroeconomics, is particularly important for studying economic divergence before the human development index (HDI) and life expectation (Snowdon and Vane 2005, 580-583). As one of the two headings mentioned above, economic development is described as determined by a society's political and economic institutions (North 1991). Institutional development plays the central role in the economic integration a country could achieve internationally or regionally (Lindberg 1963; Rodrik 2000). Based on a study pertaining to North Korea and South Korea between 1950 and 2000, Acemoglu (2003) identifies culture as the fundamental factor that led the political leaders of the two polities to choose different policies, resulting in diverse outcomes of economic development. As the study notes, before the separation, people of the two Korean regions shared the same ethnolinguistic and economic characteristics, suggesting the outcome of similar cultural behaviors. Thus, this paper attributes the effect of geographical regions (as Rodrik suggests) on living standards to regionally based cultural heritage vested in ancestors. In this paper, the term "cultural heritage" implies an intellectual tradition that drives the development of new knowledge, as shown in the series of experiments demonstrated by Mokyr (1990, 2002, 2005a).

As a slow-moving phenomenon, culture has its role in economic growth through collectively directing a population's degree of willingness to advance knowledge, such as industrial evolution. This conjecture stands on the concept of collective mental programming, articulated by Hofstede's cultural dimensions theory (e.g., Hofstede 1980, 1993, 1994, 1999, 2001; Hofstede and Bond 1988; Hofstede et al. 2010). For instance, Hofstede (1980) defines culture as "not a characteristic of individuals; it encompasses a number of people who were conditioned by the same education and life experience." Because knowledge is the engine of economic growth (Romer 1986, 1990), the implication of collective behaviors, as the enormous cross-country income inequalities implicitly indicate, represent different degrees of knowledge advancement. Past economic studies-e.g., in the series of studies by Spolaore and Wacziarg $(2009,2013 \mathrm{a}, 2013 \mathrm{~b})$-affirm the essence of culture in its identity as a determinant of technological progress. Spolaore and Wacziarg's studies propose using the approach of genetic distance to investigate effects of cultural differences between two populations separated genetically as far back as the 1500s. However, as they clarify, the measure of genetic distance does not pinpoint specific genetic effects. Williams and McGuire (2010) specifically demonstrate the culturally driven development of knowledge, based on Hofstede's cultural-dimensions theory and revealing that individualism drives economic creativity in a cross-country sample. Subsequently, individualism is determined empirically and interpreted by Gorodnichenko and Roland $(2011,2017)$ as a driver of economic growth, because this cultural dimension urges people of a country to pursue innovation in exchange for social-status rewards. The literature review on culture and economic prosperity in this paper leads to a research question: How can differences in living standards between two regions be characterized by regionally cultural disparity? Based on this paper's theoretical proposition, Asia and Europe are characterized by different dominant cultures, hypothesizing the root of living-standard divergence. 
Past studies have not addressed in particular the research inquiry mentioned above with respect to the two continents of Asia and Europe. Generally, the closest example of this research could be Spolaore and Wacziarg's (2009) as they explored barriers to entry into technological progress, discerning significant effects of cultural traits associated with genetic distances among human populations of different regions and countries. Economic divergence between the two continents has dated as far back as the 1800s (Broadberry and Gupta 2005), suggesting the era of "modern economic growth" articulated by Kuznets (1966). Britain pioneered this influential era starting approximately in the 1750s, before spreading to Western Europe and subsequently to other parts of the world (Landes 1998, 2003; Snowdon and Vane 2005, 382-589), signaling the widening era of economic divergence characterized by Kuznets (1973) as six noncultural characteristics. Thus, this paper's objective includes exploring the role of culture in relation to these characteristics of economic divergence, thereby suggesting a model to capture the intellectual problems associated with different development approaches applied to the two regions.

This paper proposes a research idea in a diagrammatic presentation, with respect to the relations between two cultural dimensions, namely individualism and power distance, ${ }^{1}$ with the six Kuznets's economic divergence characteristics (KEDCs). In comparison with the theoretical proposition, statistical scrutiny is implemented to realistically identify cultural features common to the two regions. ${ }^{2}$ The modeling approach comprising quadruple aspects of analysis is based on the theoretical proposition supported by the preliminarily statistical analysis. The main hypothesis is that causal effects from culture to standard of living are hypothesized to be different cultural dimensions of the two regions, suggesting the possibility of differences in coefficient signs and statistical significance for the cultural effects. By linking each cultural dimension with each of the six KEDCs, this paper illustrates how effectiveness of development approaches could be rooted in cultural effects, thereby suggesting the divergence of living standards between the two regions.

The remaining sections are as follows. Section 2 (Asian-European economic divergence and cultural dimensions) presents an empirically blended theoretical proposition. Section 3 shows the analytical framework including the model, data, and estimator. Section 4 reveals the cause-effect regression results, followed by discussions regarding development approaches amid economic policies. Section 5 concludes with remarks on this paper's originality and value.

\section{Asian-European economic divergence and cultural dimensions}

Great Britain, led by England, is considered the leader of modern economic growth since the eighteenth century. No evidence indicates that this was the result of political stability. Rather, strong investment in new technology and a period of rapid technological progress is asserted as the cause of this development of prosperity (Clark 1996). This phenomenon was started in Britain; however, it is not a revolution that is particular to Britain, and is generally recognized as a Western phenomenon (Mokyr 2005b). In Mokyr's perspective, technological progress led economic growth in most Western economies because of the doctrine of economic reasonableness and its significant influence on the tenets of policy makers. Mokyr also pinpoints debatable evidence regarding 
technological progress as the backbone of the industrial revolution, in that the nineteenth century saw more rapid technological development than any previous. Mokyr's understanding implies that Britain could be the leader of modern economic growth due to a common factor shared by the Western economies. According to Mokyr:

Britain's position as the lead car in the Occident Express that gathered speed in the nineteenth century and drove away from the rest of the world is of tremendous interest, but it does not tell us much about the source of power. Was Britain the engine that pulled the other European cars behind it, or was the Western world like an electric train deriving its motive power from a shared source of energy? If so what was this source? (Mokyr 2005b, 288)

As Western Europe became the region leading modern economic growth, it sparked economic divergence in some parts of the world. Kuznets (1973) explained that most countries found that adopting modern technology to follow the process of modern economic growth that Europe pioneered was not feasible, thereby suggesting six characteristics of economic divergence (Fig. 1), or Kuznets's economic divergence characteristics (KEDCs).

As stated in Mokyr's questions above, this paper attributes the "shared source of energy" to a common personality-a source of long-term, near-constant, and regionally distinct mental regulation that distinguishes the development processes of each of the two regions. Using Hofstede's cultural-dimensions theory, this source is recognized as collective mental programming. Importantly, Hofstede's (1980) study implies that human development within a nation is conditional on similar educational and life experience in a culture that differs from other nations. One cultural dimension that seems to have differentiated Asia from Western Europe is individualism. An essential behavior of an individualistic culture is the emphasis on individual achievement and leadership. Furthermore, Hofstede (1999) also determines the relationship between individualism and economic affluence, revealing that wealthier countries are typically strong in this

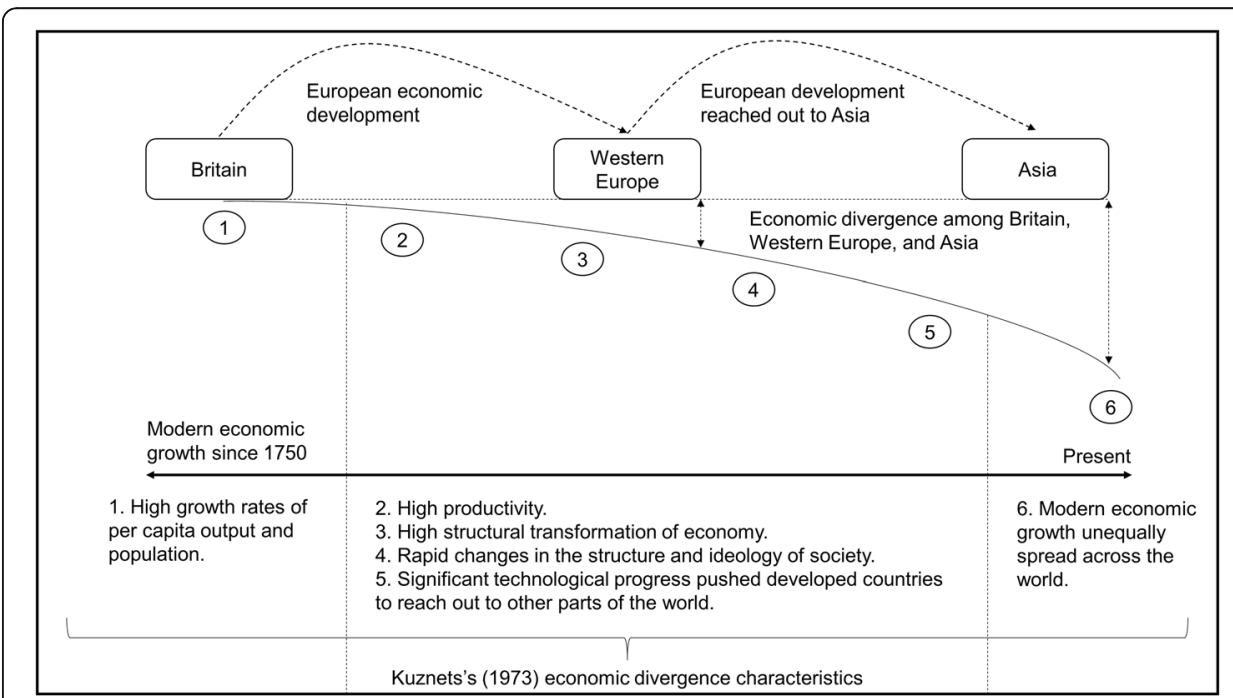

Fig. 1 The Asian-European economic divergence since the 1750s and its characteristics 
cultural dimension, while developing countries (e.g., Japan, South Korea, and Thailand) were found to have increased this cultural trait as the countries became wealthier, although more evidence is required to shed light on this aspect. Nevertheless, what could be the connection among Britain, individualism, and leadership? Was Britain ever a world leader in terms of economic development? According to an interview by Brian Snowdon and Howard R. Vane with Milton Friedman (Snowdon and Vane 2005, 212), Britain did show leadership with respect to macroeconomic research during the 1930s, signaling a transfer of macroeconomic knowledge from Britain to the United States. However, Friedman's observation was that Britain's leadership diminished significantly as orthodox opinion appeared to contradict Britain's leadership, owing to influences of the two World Wars. As mentioned above, what drove Britain's leadership seems to have been its individualistic culture. What seems normal in this leadership meltdown is that countries that raised the orthodox opinion also strongly feature this cultural dimension, particularly the United States and some other European countries, favoring Mokyr's conjecture of the shared source of energy that fueled modern economic growth.

In Fig. 1, the six Arabic sequences indicate the six KEDCs. Label 1 indicates the outcome of prosperous conditions in Britain. The eventual result is shown by Label 6, indicating enormous cross-country and regional inequalities in income per capita or living standards. This paper assumes that Labels 2-5 are the internal processes that created the gap between Labels 1 and 6. These are the four KEDCs emphasized in the following discussions.

This paper's concept (Fig. 2) pinpoints how the Asian-European economic divergence was brought about by two cultural dimensions, namely individualism and power distance. According to Hofstede (1980), individualism is generally defined as a loosely knit social framework, indicating a cultural drive that leads people to take care of themselves and their immediate families. This is opposite to a collectivist culture, in which a tight social framework emphasizing in-group loyalty (e.g., clan, relatives, and organizations) is important. In contrast, power distance generally

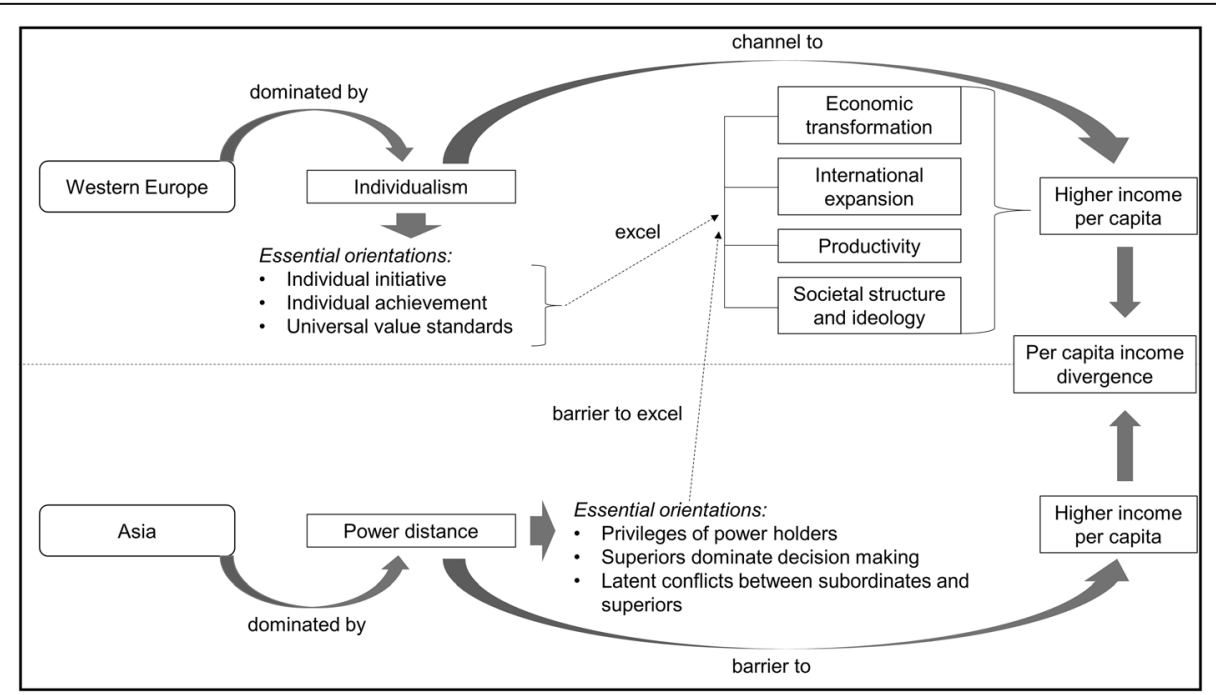

Fig. 2 Concept of culturally based economic divergence 
indicates a society's degree of acceptance of unequal distributions of power in organizations (e.g., government departments, private organizations, and universities). The two cultural dimensions can be briefly and accurately described for distinguishing the two regions in terms of economic performance. According to Hofstede's (1999) finding mentioned above, individualism could be endogenous, as it is positively influenced by an increase in a country's wealth. This paper also cannot preclude the possibility of an opposite result from the degree of power distance that is typically strong among Asian countries, suggesting that an increase in per capita income would reduce power distance and increase individualism. However, because culture is repeatedly coined as a slow-changing phenomenon in Hofstede's research, individualism could also have been historically high in Britain and Western Europe, and historically low among Asian countries, as it is an ancestral inheritance, with minor influences from the high rates of per capita income during modern economic growth since 1750. The evidence is that if there is an immense effect from per capita wealth on individualism; then why are some of the rich Asian countries (e.g., Singapore, Japan, South Korea) experiencing an enormous increase in income per capita, when during the past few decades of modern economic growth this trait of national culture remains low? As the figure shows, individualism is a dominant culture in Western Europe, whereas power distance culturally dominates Asia. The essential orientations of this cultural dimension in Fig. 2 follow Hofstede (1980) and are deemed the intrinsic qualities that either directly influence income per capita or do so indirectly through the four KEDCs (Fig. 1: Labels 2-5). The four KEDCs-economic transformation, international expansion, productivity, and social structure and ideology-occupy the same developmental space as the five forms of entrepreneurial development identified by Schumpeter (1934): new products or improved quality of goods; new production strategies; new markets; new sources of raw materials; and new industrial organization. First, conduciveness of social structure and ideology is an essential condition of an entrepreneurial process, transforming a population's understanding that economic growth is an outcome of entrepreneurship (Korsgaard and Anderson 2011). Geographic concentration represents one example of social structure influencing entrepreneurial opportunities (Sorenson and Audia 2000). Another such structure is social network, particularly as a channel of information, a source of reward, and a platform of trust that determines economic outcomes (Granovetter 2005). Second, international expansion is the channel for many profit-maximizing organizations, whereas the talent of entrepreneurs (e.g., good understanding of support services) is essential to identify genuine opportunities in the international market (Santos-Álvarez and García-Merino 2010). Third, enhancing productivity implies a firm's craftmanship of competition, particularly through advanced technology or production strategies, to create a barrier to entry or to survive the threat of new entry of technologically advanced firms (Aghion et al. 2001, 2009). Last but not least, entrepreneurial activities are also an important factor of economic transformation because entrepreneurs pursue innovation, build intermediate inputs, and raise employment opportunities and productivity (Gries and Naudé 2010). Conversely, particularly in Britain, economic transformation had played a great role in entrepreneurial development. Acemoglu et al. (2005) study the colonial Atlantic 
economies since 1500, and assert that the commercial bourgeoisie triggered changes in institutions, thereby leading to greater protection of property rights. The strong hold of property rights provided a great sense of security to innovation and entrepreneurship in Britain (North and Weingast 1989).

\section{Connection between individualism and power distance}

Why is individualism hypothesized to be essential to excellence in the four KEDCs (Fig. 1: Labels 2-5)? First of all, a country associated with a more highly individualistic national culture tends to favor and value innovative behaviors (Steenkamp et al. 1999). Furthermore, it is known to directly increase standards of living because individuals (depending on specific skills) tend to contribute to different areas of innovation in order to be recognized and rewarded socially-as Gorodnichenko and Roland (2011, 2017) contend, innovation is the social-status reward of individualism. The hypothesis that individualism promotes innovation, and economic creativity specifically, has been proved by Williams and McGuire's (2010) study using international data for more than 60 countries. An improvement to the four KEDCs and hence the overall living standards requires a constructive degree of freedom, because development of innovative ideas would not be significantly considered without the freedom of creative willpower. This is supported by a theory that creative practices require freedom and an individualistic culture has this essential feature (Shane 1992), suggesting outward-looking values in drafting and implementing development approaches amid economic policies. This also emphasizes the freedom of decentralization of decision making embedded in this culture (Eckstein 1958). The next essential reason is that having the freedom to realize creativity in development could turn out to be chaotic without proper management. According to van Hoorn (2014), a stronger individualistic culture promotes sophisticated management, as this culture favors formalization of labor relations. Last but not least, a general perspective of macroeconomics is that poor economic performance is due to excessive corruption (Aidt 2003). An individualistic culture, however, is associated with a lower degree of corrupt behaviors in a cross-country investigation (e.g., Jha and Panda 2017).

Because of its individualistic orientations, Western Europe has the advantage to excel in the four KEDCs linked deeply with the progress of innovation and entrepreneurship; whereas, the dominant culture (power distance) in Asia serves its economic prosperity unfavorably, particularly with respect to the four KEDCs. According to one proposition, low power distance signals a society's eagerness to establish an institution that favors protection against government abuse and bureaucratic power (Klasing 2013). Importantly, Klasing's study also reveals that in a case study including more than 30 countries, only power distance and individualism are found to have robust effects on institutional quality. Mihet (2013) argues that because a society instilled to a significant degree with a power-distance culture is embedded with a high authoritarian orientation, the society does not strongly emphasize an innovative ethos, which could result in poorer economic performance in the long run. In particular, Mihet's study suggests that because a high power-distance culture induces a lower level of trust among people, domestic firms in the society tend to be weak in their willingness to take risks. Furthermore, such a limited risk-taking attitude quite opposes an individualistic culture. In a high power-distance culture, high-ranking authorities could be mismatched with work 
experience. In a case study of four countries with over a thousand asset managers, heads, and chief executive officers as respondents, survey evidence reveals that high power-distance societies have the common tendency to elect senior individuals to serve in upper hierarchical positions, despite having less experience (Beckmann et al. 2008). The economic barrier owing to power distance can also impact a country internationally. For example, China is considered a high power-distance society with a score of 80 / 100 and individualism as low as 20/100 (Hofstede 2001; Hofstede et al. 2010). The cultural scores are standardized indices on a $0-100$ scale, where the higher the score the stronger the cultural dimension. The cultural differences with other economies account for part of the reduced inflow of foreign direct investment into China (Liu et al. 1997). The possibility that cultural differences between the host country (China) and home countries trigger difficulty in management adhering to the local culture justifies this finding. Another disadvantageous effect of power distance seems to be on human development. Because the quality of governmental practices is rooted in the degree of power distance, high power distance negatively affects human development (Gaygisiz 2013). These reasons remove any surprise that the dominant effect of power distance in Asia on economic prosperity is distinct from that of Western European individualism.

\section{Asia and Europe in economic prosperity}

The multipolar world economy is fueled by two major economic events taking place in Asia and Europe respectively, encouraging research on an optimal framework in international economics (Dutta 1992). This paper argues that individualism is dominant in Europe, which as a result seems to have a more successful history of economic integration in the region, in contrast to Asian economies. Evidence shows that successful economic integration in Europe has brought about convergence in per capita income, whereas such an outcome does not characterize countries belonging to the Association of Southeast Asian Nations (Karras 1997). Capannelli and Filippini (2010) highlight several obstacles to economic integration facing the two regions: East Asia (regional network of production, trade patterns, and financial cooperation) and Europe (institutionalization, monetary union, and policy structure). Notwithstanding this paper's proposition of economic divergence between Asia and Europe with respect to the two cultural dimensions, the Tiger economies should be recognized as a miracle despite the fact that these Asian economic powerhouses have a low degree of individualism. Past research also recognizes the Tiger economies' outstanding economic performances as a miracle of factor accumulation (Snowdon and Vane 2005, 614; Young 1992, 1994, 1995). The Tiger economies are alternatively known as the Asian Five Dragons in Geert Hofstede's research, adding Japan to the list. Hofstede and Bond (1988) suggest that the secret of the Asian Five outperformance of all other Asian economies is their feasibility of accepting technologies from some Western economies. Nonetheless, although individualism is low overall in Asia, based on this paper's theoretical proposition, it is not the dominant culture in the region, hence the low degree of individualism is not expected to generate any adverse impact on the Asian economic prosperity; in contrast, the cultural dominance of power distance is expected 
to be a significant barrier to advancing economic prosperity in Asia, putting a gap between Asia and Europe in terms of living standards.

\section{Analytical framework}

\section{A preliminary analytic}

This paper's intention is to perform a quadruple modeling based on regional differences between Asia and Europe. A further distinction is made between Western Europe and other European countries. The four equations share the same model specification estimated respectively, using panel data on four Eurasian groups: Eurasia, Europe, Asia, and Western Europe. This empirical design highlights the significance of regional development approaches, amid economic policies described in this paper, particularly when the objective is to determine the relationship between cultural dimensions and economic prosperity. A preliminary inspection reveals how Asia and Europe differ in four cultural dimensions, namely power distance, individualism, masculinity, and uncertainty avoidance (Fig. 3). Twenty-six countries, 13 Asian and 13 European (including three Western European countries) were drawn randomly from each region (selecting a larger number of countries was restricted due to data limitations). The medians of a pair of boxplots under each cultural dimension reveal differences between the two regions, which are vastly visible across the four cultural dimensions. This graphical plot of statistical scores favors the theoretical framework of dominant culture shown in Fig. 2. In addition to power distance and individualism discussed in the previous section, two other cultural dimensions (masculinity and uncertainty avoidance) are also used. These supplementary dimensions are usually tested in the literature along with individualism and power distance, including some of the studies mentioned previously. The latter dimensions are also added based on observed correlations with the two primary dimensions. Table 1 shows the descriptive statistics of all variables. No high correlations are observed, whereas medium-level

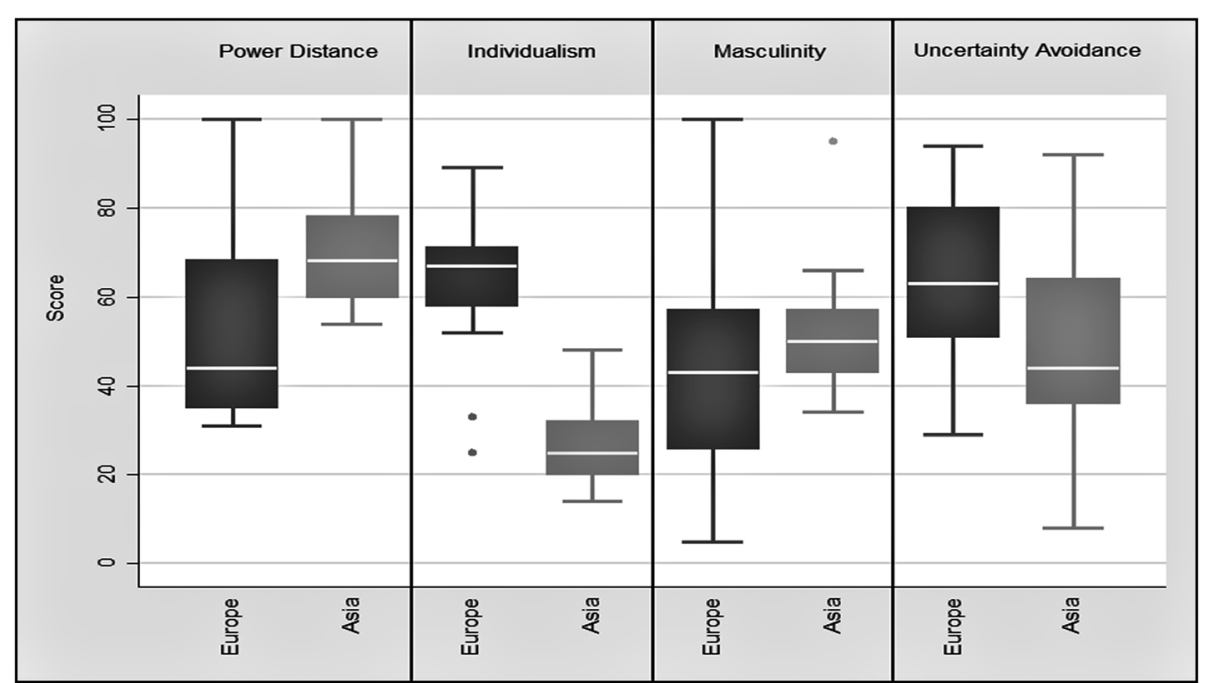

Fig. 3 Regional differences in four cultural dimensions. Notes: The figure is created by the author using the cultural-dimension data provided by the Hofstede Insights website (main references: Hofstede 2001; Hofstede et al. 2010) 
Table 1 Descriptive and correlation statistics

\begin{tabular}{|c|c|c|c|c|}
\hline \multicolumn{5}{|l|}{ Panel A: Descriptive statistics (panel dataset) } \\
\hline & & \multicolumn{3}{|c|}{ Mean (Standard deviation) } \\
\hline & Observation & Asia and Europe & Asia & Europe \\
\hline $\mathrm{HDI}$ & 104 & $\begin{array}{l}0.765 \\
(0.138)\end{array}$ & $\begin{array}{l}0.683 \\
(0.149)\end{array}$ & $\begin{array}{l}0.830 \\
(0.069)\end{array}$ \\
\hline Power distance & 104 & $\begin{array}{l}62.5 \\
(20.510)\end{array}$ & $\begin{array}{l}71.308 \\
(13.926)\end{array}$ & $\begin{array}{l}53.692 \\
(22.304)\end{array}$ \\
\hline Individualism & 104 & $\begin{array}{l}44.5 \\
(22.369)\end{array}$ & $\begin{array}{l}27.231 \\
(11.210)\end{array}$ & $\begin{array}{l}61.769 \\
(16.635)\end{array}$ \\
\hline Masculinity & 104 & $\begin{array}{l}47.5 \\
(22.179)\end{array}$ & $\begin{array}{l}52.923 \\
(25.331)\end{array}$ & $\begin{array}{l}42.077 \\
(26.428)\end{array}$ \\
\hline Uncertainty avoidance & 104 & $\begin{array}{l}57.038 \\
(22.584)\end{array}$ & $\begin{array}{l}49.615 \\
(22.932)\end{array}$ & $\begin{array}{l}64.462 \\
(19.794)\end{array}$ \\
\hline Real per capita gross domestic product & 104 & $22,692.92(21,518.39)$ & $\begin{array}{l}12,894.69 \\
(15,814.85)\end{array}$ & $\begin{array}{l}32,491.15 \\
(22,119.59)\end{array}$ \\
\hline \multicolumn{5}{|c|}{ Panel B: Correlation statistics (panel dataset combining Asia and Europe) } \\
\hline & $\mathrm{HDI}$ & Power distance & Individualism & Masculinity \\
\hline Power distance & -0.381 & & & \\
\hline Individualism & 0.526 & -0.598 & & \\
\hline Masculinity & -0.066 & 0.487 & -0.147 & \\
\hline Uncertainty avoidance & 0.146 & -0.087 & 0.140 & 0.062 \\
\hline \multicolumn{5}{|l|}{ Panel C: List of countries } \\
\hline Asia & & Europe & & \\
\hline China & Nepal & Belgium & Latvia & \\
\hline Hong Kong & Pakistan & Croatia & Norway & \\
\hline India & Philippines & Czech Republic & Serbia & \\
\hline Indonesia & Singapore & Estonia & Slovakia & \\
\hline Iran & South Korea & Finland & Sweden & \\
\hline Japan & Thailand & France & United Kingdom & \\
\hline Malaysia & & Germany & & \\
\hline \multicolumn{5}{|c|}{ Panel D: List of Western-Europe countries (including two southwestern countries) } \\
\hline Belgium & Netherlands & Ireland & Spain & \\
\hline France & Portugal & Luxembourg & United Kingdom & \\
\hline
\end{tabular}

correlations exist (Table 1: Panel B). For the models discussed in the following section, the first three model equations are based on the same number of countries for Asia and Europe (Table 1: Panel C). The fourth model equation is based on a purely Western-European sample that has eight countries, including five countries not included in the sample of 13 random European countries mentioned above (Table 1: Panel D).

\section{Modeling}

The data analysis includes performing a quadruple modeling with respect to the four groups of the Eurasian region: Eurasia, Europe, Asia, and Western Europe. Similarly, four equations are specified and expected to differ empirically by region. This modeling conveys an important value, as it focuses on the economic prosperity of one region and 
compares subregions within it, particularly as a sociological approach recognizes that culture shapes progress in economic growth and development (Grief 2003; Harrison 2000; Huntington 1996; Landes 1998). For example, Harrison (2000) contends, "The crucial element that has been largely ignored is the cultural: that is to say, values and attitudes that stand in the way of progress." (55). Although economists have now popularized the study of culture in understanding economic development, as described in the theoretical proposition above, crucial findings have not been revealed. Twenty-six countries, evenly divided between Asia and Europe, are randomly selected (data limitation prohibited selecting a larger number of countries). The pure Western-Europe sample has eight countries, as presented in Table 1. The model is presented as:

$$
\ln Y_{i t}^{R}=\alpha+\phi_{i} \sum_{i=1}^{3} T_{i}+\beta_{1} H D_{i \lambda}+\beta_{2} P O W_{i}+\beta_{3} I N D_{i}+\beta_{4} M A S_{i}+\beta_{5} U N C_{i}+\mu_{i t} .
$$

In Eq. (1), the dependent variable $\left(Y_{i t}^{R}\right)$, indicates living standards measured by real income per capita (e.g., Snowdon and Vane 2005, 580-583). The regional index distinguishes the four groups of Eurasia ( $R=$ Eurasia, Europe, Asia, and Western Europe). Data on the dependent variable are in panel form, where $i$ subscript is a cross-sectional unit and $t$ subscript is a time-series unit. The four cultural dimensions are abbreviated as $P O W_{i}$ (power distance), $I N D_{i}$ (individualism), $M A S_{i}$ (masculinity), and $U N C_{i}$ (uncertainty avoidance). Based on the literature review above, this model is controlled with the degree of human development, education (also a proxy for technological progress), and income per capita. These possible confounders are measured by the human development index $\left(H D_{i \lambda}\right)$, where $\lambda$ indicates 4 years $(1990,2000,2010$, and 2015). The living standards variable (dependent variable) is measured as a five-year average (1998-2002, 2003-2007, 2008-2012, and 2013-2017). In addition, the model is also controlled with time-specific effects, as indicated by the summation term for $T_{i t}$, for the four periods mentioned above.

\section{Method and procedure of estimation}

The baseline method is a pooled ordinary least squares (OLS), and this method offers the simplicity to implement specification tests such as heteroskedasticity and linearity. This paper uses the method developed by Breusch and Pagan (1979) and Cook and Weisberg (1983), where the null hypothesis assumes a constant variance. The linearity test uses the Ramsey Regression Equation Specification Error Test (RESET) statistic; as Wooldridge (2010) explains, "It can only test whether the expected value of $y$ given the variables actually in the regression is linear in those variables." (125), where $y$ in the statement is the dependent variable.

A random-effect panel-data method is the main estimator. The generalized least squares (GLS) method is used, thereby controlling for random effects from unobserved heterogeneity uncorrelated with the independent variables. Supplementary statistics such as R squared and random-effect test are obtained. Random effects that are significant indicate that OLS is less consistent than a random-effect GLS. This paper's final estimator is the maximum likelihood estimator (MLE), believed to be more efficient than other estimators including GLS (Wooldridge 2010, 385). Nevertheless, this paper 
uses GLS for simplicity to implement the random-effect Lagrange multiplier test introduced by Breusch and Pagan (1980), thereby testing the null hypothesis that the variance of random effects is zero. Information criteria such as the Akaike information criterion (AIC) and Bayesian information criterion (BIC) are obtained from the MLE regressions (Akaike 1973, 1974; Schwarz 1978). MLE is to be used primarily for all equations mentioned previously, whereas diagnostic tests from OLS and GLS are used to establish the specification validity for MLE based on the baseline sample (Eurasia). For other samples (Asia, Europe, and Western Europe), OLS and GLS are not to be repeated.

In terms of modeling setting, OLS is usually the default setting for regression analysis. When random effects are deemed present, a random-effect GLS or MLE is the option, where the study prefers to implement both methods because the calculation of some statistics (e.g., R squared and random-effect test) are more feasible with GLS than MLE. On the other hand, MLE is regarded to be more efficient than GLS according to Wooldridge's (2010) textbook econometrics due to its efficiency properties, while MLE can also yield a consistent estimation given that the model is correctly specified. First, this study verifies the linear functional form using the Ramsey RESET test. Second, this study verifies the validity of random-effect specification using the Breusch-Pagan test. Third, this paper assumes a normal distribution for the errors and verifies that the errors follow a normal distribution using the Jarque-Bera test of normality (Jarque and Bera 1987). In the normality test, the null hypothesis is that the regression errors meet the condition of the normal distribution. MLE can be even more efficient than three-stage least squares and generalized method of moments if the normal distribution of errors is satisfied (Amemiya 1977; Wooldridge 2010). The remaining issue could be correlations between the errors and independent variables, the possibility of which the study addresses by controlling for the confounding factors as previously explained. This paper does not implement a fixed-effect model because the cultural variables are measured in cross-sectional unit without time-series dimension. Thus, it is implausible to estimate a fixed-effect model and therefore a comparison with the random-effect model is not implemented. Overall, this setting of empirical modeling is developed with the notion of obtaining efficient and consistent regression results. As found in the following results, matching the theoretical predictions of this paper gives rise to another sense to believe that such a modeling setting is accurate. For instance, power distance is also found to have a negative effect on economic performance in opposition to the positive effect of individualism, which is not only consistent with the theoretical proposition but also (both directly and indirectly) consistent with the empirical evidence shown by the past studies mentioned in Section 2 (Asian-European economic divergence and cultural dimensions). In addition to being consistent theoretically and empirically with the literature, this modeling setting is deemed an advantage over past studies as this paper argues that regional differences in culture must be considered, which contributes to the accuracy of the modeling setting. The study does not provide the technical details of the three methods because these estimators are commonly known and applied in social science research. The study uses Stata (version 14) statistical software package to estimate all OLS, GLS, and MLE regressions. EViews (version 8) is used as a supplementary software package, particularly for confirming certain diagnostic-test results obtained by Stata. 
Data on cultural dimensions for the 26 countries are sourced from the Hofstede Insights 2018 website (main references: Hofstede 2001; Hofstede et al. 2010). The HDI data for the four periods mentioned previously are provided by the Human Development Report of the United Nations Development Programme (Human Development Data 1997-2017). The HDI data comprise the values of three essential aspects: income per capita, education, and life expectancy. The values of HDI are generally later than the periods for the dependent variable (living standards). The data on the dependent variable, measured as contemporary real gross domestic product (GDP) per capita (constant 2010 United States dollar (US\$)) in five-year averages from 1998 to 2017, are obtained from the World Development Indicators of the World Bank (World Bank DataBank 2018).

\section{Results}

\section{Validity and reliability of model specification}

The first set of results (Table 2) is based on the sample consisting of both Asian and European countries. The OLS regression rejects the possibility of heteroskedasticity

Table 2 Pooled versus random-effect regressions, Eurasia region

\begin{tabular}{|c|c|c|c|}
\hline Dependent variable: Real GDP per capita (log) & $\begin{array}{l}\text { Pooled } \\
\text { OLS }\end{array}$ & $\begin{array}{l}\text { Random-effect } \\
\text { GLS }\end{array}$ & $\begin{array}{l}\text { Random-effect } \\
\text { MLE }\end{array}$ \\
\hline \multicolumn{4}{|l|}{ Independent variables: } \\
\hline Human development & $\begin{array}{l}10.246\{1.016\} \\
(0.288)^{* * *}\end{array}$ & $\begin{array}{l}6.947\{0.689\} \\
(0.539)^{* * *}\end{array}$ & $\begin{array}{l}4.154\{0.412\} \\
(0.636)^{* * *}\end{array}$ \\
\hline Power distance & $\begin{array}{l}-0.007\{-0.108\} \\
(0.002)^{* * *}\end{array}$ & $\begin{array}{l}-0.010\{-0.148\} \\
(0.005)^{* *}\end{array}$ & $\begin{array}{l}-0.013\{-0.192\} \\
(0.009)\end{array}$ \\
\hline Individualism & $\begin{array}{l}-0.0001\{-0.002\} \\
(0.0019)\end{array}$ & $\begin{array}{l}0.009\{0.145\} \\
(0.005)^{*}\end{array}$ & $\begin{array}{l}0.016\{0.258\} \\
(0.008)^{* *}\end{array}$ \\
\hline Masculinity & $\begin{array}{l}0.002\{0.031\} \\
(0.002)\end{array}$ & $\begin{array}{l}0.003\{0.048\} \\
(0.004)\end{array}$ & $\begin{array}{l}0.004\{0.064\} \\
(0.007)\end{array}$ \\
\hline Uncertainty avoidance & $\begin{array}{l}-0.003\{-0.045\} \\
(0.001)^{* * *}\end{array}$ & $\begin{array}{l}-0.001\{-0.017\} \\
(0.003)\end{array}$ & $\begin{array}{l}-0.0002\{-0.003\} \\
(0.006)\end{array}$ \\
\hline Time-specific effect 2003-2007 & $\begin{array}{l}-0.455\{-0.143\} \\
(0.085)^{* * *}\end{array}$ & $\begin{array}{l}-0.247\{-0.077\} \\
(0.053)^{* * * *}\end{array}$ & $\begin{array}{l}-0.070\{-0.022\} \\
(0.049)\end{array}$ \\
\hline Time-specific effect 2008-2012 & $\begin{array}{l}-0.914\{-0.287\} \\
(0.090)^{* * *}\end{array}$ & $\begin{array}{l}-0.520\{-0.163\} \\
(0.076)^{* * *}\end{array}$ & $\begin{array}{l}-0.186\{-0.058\} \\
(0.081)^{* *}\end{array}$ \\
\hline Time-specific effect 2013-2017 & $\begin{array}{l}-1.009\{-0.316\} \\
(0.092)^{* * *}\end{array}$ & $\begin{array}{l}-0.550\{-0.173\} \\
(0.085)^{* * *}\end{array}$ & $\begin{array}{l}-0.161\{-0.050\} \\
(0.093)^{*}\end{array}$ \\
\hline Intercept & $\begin{array}{l}2.721 \\
(0.251)^{* * *}\end{array}$ & $\begin{array}{l}4.612 \\
(0.558)^{* * *}\end{array}$ & $\begin{array}{l}6.213 \\
(0.902)^{* * *}\end{array}$ \\
\hline Observations & 104 & 104 & 106 \\
\hline Countries & 26 & 26 & 26 \\
\hline Adjusted R squared & 0.954 & & \\
\hline R squared & & 0.922 & \\
\hline Heteroskedasticity test & $0.04[0.840]$ & & \\
\hline Linearity test & $1.81[0.152]$ & & \\
\hline Random-effect test & & $55.27[0.000]$ & \\
\hline Normality test (residuals) & & & $1.722[0.423]$ \\
\hline $\mathrm{AIC} / \mathrm{BIC}$ & & & $-21.774 / 7.314$ \\
\hline
\end{tabular}

Notes: Estimates for each independent variable are as original coefficient \{standardized coefficients\} (standard errors). Values in square brackets are probability values. The symbols ${ }^{* * *},{ }^{* *}$, and ${ }^{*}$ denote significance at the $1 \%, 5 \%$, and $10 \%$ levels, respectively 
and nonlinearity. Nevertheless, the random-effect GLS regression rejects the possibility that OLS is more consistent than a random-effect regression. Multicollinearity is precluded as a result of weak correlations among the independent variables, as discussed previously. The predictability of living standards using Eq. (1) is above $92 \%$. What does the $0.92 \mathrm{R}$ squared imply? Since this model focuses primarily on the set of cultural dimensions, the high $\mathrm{R}$ squared does not mean that unincluded variables such as human capital, physical capital, and stock of knowledge are unimportant (as primary variables in the endogenous growth theory). Implicitly, these essential economic factors are subsumed under the cultural dimensions. This assumption is also made by some of the studies (related to cultural dimensions) mentioned previously. With respect to endogeneity or confounding issues, this paper has controlled for three possible confounders: lagged values of income per capita, education level, and life expectancy, suppressed into one variable (HDI in $\lambda$ years). On the other hand, the reliability of the model is judged in terms of theoretical consistency, as discussed with the three figures. Furthermore, the robustness of findings is evaluated based on different sub-samples: Asia, Europe, and Western Europe. Last but not least, the Jarque-Bera test on the MLE regressions confirms that the errors (residuals) follow a normal distribution, which is an essential condition for consistent estimation.

\section{The Asia-Europe regression results}

Assuming that individualism and power distance have the same effects for Asia and Europe could produce weak evidence of the relationship between culture and living standards. The results in Table 2 justify this argument. First, from the random-effect MLE regression results, the merely significant effect among the four cultural dimensions is found to be individualism. This appears to be consistent with the finding of Gorodnichenko and Roland (2011, 2017), as they adhere to a sensible justification mentioned previously, suggesting that the only significant cultural dimension in Table 2 (column 4) seems to have its own merit. However, this paper argues that this finding is rationally weak, in the sense that we strictly assume Asia and Europe incur the same cultural effects on economic prosperity. For example, this finding tells policy makers to be committed to an individualistic culture, including individual achievement, individual initiative, and universal value standards (Fig. 2), which motivate individual participation in entrepreneurship. As a result, policy makers hope the development of entrepreneurship could bring about higher rates of employment and innovation, improving the overall living standards. However, this single cultural dimension does not strongly merit an interpretation of similar economic consequences from a regional perspective. This paper interprets that a one-standard-deviation increase in individualistic score leads to a 0.258 standard-deviation increase in living standards, which is acceptable but rationally weak because the differences between Asian and European cultures have not been considered. In order to prove this argument, this paper separates the estimation by region, as follows.

The Asia, Europe, and Western Europe regression results

In Table 3 (columns 2 and 3), the four cultural dimensions show apparently different effects on living standards in Asia and in Europe. The effect of individualism on the 
Table 3 Random-effect maximum likelihood regressions, comparing Asia, Europe, and Western

\begin{tabular}{llll} 
Europe & & & \\
\hline $\begin{array}{l}\text { Dependent variable: } \\
\text { Real GDP per capita (log) }\end{array}$ & Asia & Europe & Western Europe \\
\hline Independent variables: & & & \\
Human development & $9.251\{0.966\}$ & $0.916\{0.079\}$ & $2.220\{0.293\}$ \\
Power distance & $(0.736)^{* * *}$ & $(1.018)$ & $(3.127)$ \\
& $-0.014\{-0.136\}$ & $-0.009\{-0.251\}$ & $-0.064\{-2.231\}$ \\
Individualism & $(0.006)^{* * *}$ & $(0.012)$ & $(0.019)^{* * *}$ \\
& $-0.008\{-0.063\}$ & $0.026\{0.540\}$ & $0.018\{0.776\}$ \\
Masculinity & $(0.006)$ & $(0.012)^{* *}$ & $(0.009)^{* *}$ \\
& $0.010\{0.107\}$ & $0.0004\{0.013\}$ & $0.005\{0.199\}$ \\
Uncertainty avoidance & $(0.005)^{* *}$ & $(0.007)$ & $(0.005)$ \\
Time-specific effect 2003-2007 & $-0.006\{-0.096\}$ & $0.001\{0.025\}$ & $0.041\{2.358\}$ \\
Time-specific effect 2008-2012 & $(0.003)^{*}$ & $(0.008)$ & $(0.013)^{* * *}$ \\
& $-0.454\{-0.139\}$ & $0.137\{0.075\}$ & $-0.063\{-0.065\}$ \\
Time-specific effect 2013-2017 & $(0.076)^{* * *}$ & $(0.067)^{* *}$ & $(0.244)$ \\
Intercept & $-0.932\{-0.285\}$ & $0.163\{0.089\}$ & $-0.136\{-0.140\}$ \\
Observations & $(0.117)^{* * *}$ & $(0.106)$ & $(0.350)$ \\
Countries & $-0.994\{-0.304\}$ & $0.206\{0.112\}$ & $-0.120\{0.124\}$ \\
Normality test (residuals) & $(0.133)^{* * *}$ & $(0.121)^{* *}$ & $(0.390)$ \\
AlC/BIC & 3.855 & 8.058 & 7.686 \\
\hline Notes: Estima & $(1.348)^{* * *}$ & $(2.234)^{* * *}$ \\
& $(0.662)^{* * *}$ & 52 & 32 \\
& 52 & 13 & 8 \\
& 13 & $3.078[0.215]$ & $4.026[0.134]$ \\
& $1.148[0.563]$ & $-19.085 / 2.379$ & $-10.391 / 4.266$ \\
\hline
\end{tabular}

Notes: Estimates for each explanatory variable are as original coefficient \{standardized coefficients\} (standard errors). Values in square brackets are probability values. The symbols ${ }^{* *}, * *$, and ${ }^{*}$ denote significance at the $1 \%, 5 \%$, and $10 \%$ levels, respectively

regression for Europe appears to be much more economically significant compared to that in Table 2, indicating that the lower effect found in Table 2 (column 4) is a result of being pulled downward by the low degree of individualism among the Asian countries. In contrast, the absence of high individualism in Asia renders an insignificant effect on living standards (Table 3: column 2). As theoretically predicted by this paper, power distance has a negative impact on living standards, suggesting the adverse effects brought about by the three orientations shown in Fig. 2. This yields 0.136 standard-deviation lower living standards for a one-standard-deviation increase in power distance (Table 3: column 2). In addition, uncertainty avoidance also negatively affects living standards, as it discourages change in status quo in exchange for certainty, thereby reducing living standards as the world economy becomes more competitive. Nevertheless, living standards in the Asian region seem to be supported by its intermediate-level masculine culture, which crowds out a big portion of the negative influences due to the region's strong power distance. The role of individualism increases further as the estimation on the Western Europe region shows (Table 3: column 4). Great Britain is the leader of individualism in the world, while Western Europe has an overall strong degree of individualism. Thus, a one-standard-deviation increase in this cultural dimension yields approximately 0.236 standard-deviation higher living standards than that entailing the 13 European countries. Western Europe also shows additional effects of culture. Particularly, the results show a significantly positive effect of uncertainty avoidance. In contrast to 
Asia, Europe's uncertainty avoidance emphasizes the need to strengthen living standards, which stems from the fact that many European countries are developed economies and eager to maintain this status as competition in the world economy increases. The opposite effects of uncertainty avoidance between the two regions suggest one essential idea, namely the preference to preserve the status quo. Nevertheless, this conclusion requires further research to confirm, which is beyond the scope of this paper.

\section{Discussion: impacts on economic policies}

The success of macroeconomic management relies on the economic policies most likely to achieve high rates of growth and employment with low inflation. Countries in Asia and Europe may use the same development approaches; however, practices could be different due to different cultures and lead to differences in economic outcomes. The high level of individualism in Europe could be the reason why the region successfully establishes unified economic policies, particularly the European Union, and hence attains much stronger economic success than its Asian counterparts. In contrast, the Asian countries could face a barrier to advanced regional unification of economic policies due to the strength of their power-distance culture. Nevertheless, the reality shows that this region has made good progress in fine-tuning its regional economic cooperation, signaling the positive effect of its intermediate-level masculine culture. Another aspect of that culture is the relatively higher degree of uncertainty avoidance among the Western European countries, which produces a positive effect in opposition to the negative effect in Asia. As a result, Western Europe has the grim determination to strengthen living standards, apparently much stronger than that of the Asian countries. Although the degree of uncertainty avoidance is not statistically significant in the overall Europe sample, it does show a positive coefficient.

While the findings show that Asia's power distance is a barrier to achieving better living standards, its innovation rates (from some countries) are rapidly formed and contribute to living standards. The intermediate level of a masculine culture seems to be the driving force behind Asia's burgeoning innovative activities. As stated by Hofstede (1999), one essential characteristic of masculinity is that people in the society emphasize a competitive performance, assertiveness, and material success. The paper's theoretical proposition and findings imply that if Asian countries could lower the degree of power distance collectively, the region as a whole can boost its performance of innovation (economic development), thereby bringing about even more prosperity and improved living standards. Despite Asian countries' fast technological progress, most of the countries are still lagging behind the European countries in terms of per capita income, suggesting a gap in living standards due to different cultural effects that past studies have not explored. For example, the average growth rate of China's patent applications by residents from 1990 to 2016 is $23.7 \%$ and Vietnam shows $12.2 \%$, whereas Germany shows a much smaller average growth rate of $1.8 \%$ and the United Kingdom experienced a negative growth rate of $1.2 \%$. In terms of living standards, China experienced an average growth of real income per capita of 9\% in the period 1990-2016 and Vietnam shows 5.5\%, whereas Germany and the United Kingdom each experienced a smaller average growth of $1.4 \%$ and $1.5 \%$, respectively. Notwithstanding the tremendous innovation rates of China and Vietnam, the two Asian countries are still behind 
Germany and the United Kingdom in terms of living standards. For example, the gap in real income per capita between Germany and China was US\$31606.33 in 1990, the gap became US\$39028.54 in 2016, showing a US\$7422.21 increase in the difference in living standards. The gap is even more apparent with Vietnam, Germany was far ahead of Vietnam in 2016 with a US\$44187.72 higher in real income per capita compared with US\$31905.22 in 1990. The statistical evidence is calculated using data provided by the World Development Indicators, patents are measured as the number of patent applications by residents and the real income per capita is as described previously. This statistical evidence pinpoints differences in living standards that are not reduced by the faster pace of innovation in Asia than Europe for nearly three decades, thereby signaling the possible effects of cultural differences proposed by this paper. This statistical evidence is generalizable to many other Asian countries. Furthermore, including the few Asian countries that show the miracle of outstanding improvements in living standards in the regressions does not eliminate the significant effects of culture shown by this paper. For example, Singapore is considered outstanding in terms of real income per capita, whereas it is still lagging behind Norway. This explanation also suggests a significant social value from recognizing cultural influences on the economic development in the two regions.

\section{Conclusions}

This paper highlights the importance of culture to economic prosperity, comparing Asia and Europe, and suggesting that living standards are higher in Europe than in Asia because of two polarized cultural dimensions. The theory pinpoints the polarization between individualistic and power-distance cultures, thereby attributing to each region a dominant cultural dimension. This theory explains economic divergence between the regions, with the consequence of a lower living standard in one region.

This paper illustrates a policy implication of culture for economic prosperity by distinguishing the cultural effects on Asia and Europe respectively. An individualistic culture is identified to favor Europe's economic prosperity while the power-distance culture is found to be a barrier to development in Asia. This shows a potentially destructive effect if a successful development approach in Europe was assumed ipso facto to work similarly effectively in Asia. For instance, economic integration in Europe unifies economic policies, whereas the world has witnessed that such economic integration in Asia does not work as effectively as in Europe. This paper shows that this discrepancy in economic outcomes is due to Asia's high degree of power distance. Nevertheless, the intermediate-level masculine culture in Asia, characterized by assertiveness, independence, and material rewards, entails a cultural advantage that is not found significantly in Europe.

As more studies have shown the economic significance of cultural dimensions, this paper contributes a unique finding by vigilantly hypothesizing how Asia's and Europe's economic prosperity can be distinguished by culture. The social value of culture in an economy is identified empirically and the findings suggest that policy makers should take regional differences in culture into account as they adopt development approaches from other regions. A vigilant modification of the development approaches to maximize the values of existing economic policies may be needed. If the government realizes the economic effects of culture and is willing to modify development approaches, this 
paper's findings suggest that there would be a marginal gain toward a better standard of living. One limitation facing this paper is the barrier to concluding how variation of culture over time could influence the development values of economic policies.

\section{Endnotes}

${ }^{1}$ The concepts of individualism and power distance were introduced by Geert Hofstede, who specializes in social psychology. As explained by Hofstede (1980), individualism is a collective mental programming inherited by people within a country. People of an individualistic society do not view close individual relationships as important (e.g., emotional dependence is weak), whereas people of this culture emphasize emotional independence, individual initiative, and achievement. In contrast, the opposite culture to individualism is collectivism in which in-group emotional dependence is emphasized. On a 0-100 scale, a society with an individualism score higher than 50 can be considered an individualistic society. For example, a society with an individualistic score of 51, such as Spain, is found to be oriented by individualism (Hofstede 2001; Hofstede et al. 2010). A score of 50 suggests an equal orientation between individualism and collectivism. Hofstede (1980) defines power distance to be an unequal favoritism of power in institutions and organizations. In a society oriented by power distance, superiors in institutions and organization are entitled to privileges. Similarly, based on Hofstede (2001) and Hofstede et al. (2010), societies with a score higher than 50 (e.g., Japan is given a score of 54) can be described as power-distance oriented

${ }^{2}$ Europe and Asia are each a regional collection of countries known to be separated by common geographical landmarks, namely the Black Sea with its outlets, Bosporus, Caucasus Mountains, Caspian Sea, Dardanelles, Ural Mountains, and Ural River (National Geographic Society 1999). In this paper, because of data limitation, it is implausible to consider all countries of the two regions. Nevertheless, countries exhibit a strong culture marking the cultural differences between Asia and Europe, so it is important properly to represent each region and these countries are in the samples. According to this paper's theoretical proposition and empirical observation, European countries can be considered generally as an individualism-oriented region, whereas Asian countries can be considered generally as a power-distance oriented region. Therefore, excluding some of the countries (e.g., Italy, Poland, Turkey, and Vietnam) from each region is not deemed significantly to contradict the theoretical proposition introduced by the study.

\section{Abbreviations}

AIC: Akaike information criterion; BIC: Bayesian information criterion; GDP: Gross domestic product; GLS: Generalized least squares; HDI: Human Development Index; KEDCs: Kuznets's economic divergence characteristics; MLE: Maximum likelihood estimator; OLS: Ordinary least squares; RESET: Ramsey Regression Equation Specification Error Test; US\$: United States dollar

\section{Acknowledgements}

The author would like to thank the editors and anonymous reviewers for providing useful comments.

Funding

Not applicable.

Availability of data and materials

The data that support the findings of this study are available from the World Development Indicators of the World Bank (https://databank.worldbank.org/data/source/world-development-indicators), the Human Development Index of the United Nations Development Programme (http://hdr.undp.org/en/indicators/137506), and the Country Comparison Tool of the Hofstede Insights website (https://www.hofstede-insights.com/product/compare-countries/). 
Authors' contributions

This paper is single-authored and the research was performed entirely by the author. The author read and approved the final manuscript.

\section{Competing interests}

The author declare that he has no competing interests.

\section{Publisher's Note}

Springer Nature remains neutral with regard to jurisdictional claims in published maps and institutional affiliations.

Received: 15 October 2018 Accepted: 2 January 2019

Published online: 11 January 2019

\section{References}

Acemoglu, Daron. 2003. Why not a political Coase theorem? Social conflict, commitment, and politics. Journal of Comparative Economics 31 (4): 620-652.

Acemoglu, Daron, Simon Johnson, and James Robinson. 2005. The rise of Europe: Atlantic trade, institutional change and growth. American Economic Review 95 (3): 546-579.

Aghion, Philippe, Richard Blundell, Rachel Griffith, Peter Howitt, and Susanne Prantl. 2009. The effects of entry on incumbent innovation and productivity. Review of Economics and Statistics 91 (1): 20-32.

Aghion, Philippe, Christopher Harris, Peter Howitt, and John Vickers. 2001. Competition, imitation and growth with step-bystep innovation. Review of Economic Studies 68 (3): 467-492.

Aidt, T.S. 2003. Economic analysis of corruption: A survey. Economic Journal 113 (491): F632-F652 doi.org/10.1046/j.0013-0133. 2003.00171.x

Akaike, Hirotugu. 1973. Information theory and an extension of the maximum likelihood principle. In Second international symposium on information theory, ed. Boris N. Petrov and Frigyes Csáki, 267-281. Budapest: Akailseoniai-Kiudo.

Akaike, Hirotugu. 1974. A new look at the statistical model identification. IEEE Transactions on Automatic Control 19 (6): $716-723$.

Amemiya, T. 1977. The maximum likelihood and the nonlinear three-stage least squares estimator in the general nonlinear simultaneous equation model. Econometrica 45 (4): 955-968 doi.org/10.2307/1912684.

Beckmann, D., L. Menkhoff, and M. Suto. 2008. Does culture influence asset managers' views and behavior? Journal of Economic Behavior \& Organization 67 (3-4): 624-643 doi.org/10.1016/j.jebo.2007.12.001.

Breusch, T.S., and A.R. Pagan. 1979. A simple test for heteroscedasticity and random coefficient variation. Econometrica 47 (5): 1287-1294 doi.org/10.2307/1911963.

Breusch, T.S., and A.R. Pagan. 1980. The Lagrange multiplier test and its applications to model specification in econometrics. Review of Economic Studies 47 (1): 239-253 doi.org/10.2307/2297111.

Broadberry, S., and B. Gupta. 2005. The early modern great divergence: wages, prices and economic development in Europe and Asia, 1500-1800. Economic History Review 59 (1): 2-31 doi.org/10.1111/j.1468-0289.2005.00331.x.

Capannelli, G., and C. Filippini. 2010. Economic integration in East Asia and Europe: lessons from a comparative analysis. Singapore Economic Review 55 (1): 163-184 doi.org/10.1142/S0217590810003651.

Clark, G. 1996. The political foundations of modern economic growth: England, 1540-1800. Journal of Interdisciplinary History 26 (4): 563-588 doi.org/10.2307/205042

Cook, R.D., and S. Weisberg. 1983. Diagnostics for heteroscedasticity in regression. Biometrika 70 (1): 1-10 doi.org/10.1093/ biomet/70.1.1.

Dutta, Manoranjan J. 1992. Economic regionalization in Western Europe: Asia-Pacific economies (macroeconomic core: microeconomic optimization). American Economic Review 82 (2): 67-73.

Eckstein, Alexander. 1958. Individualism and the role of the state in economic growth. Economic Development and Cultural Change 6 (2): 81-87.

Gaygısız, E. 2013. How are cultural dimensions and governance quality related to socioeconomic development? Journal of Socio-Economics 47 (December): 170-179 doi.org/10.1016/j.socec.2013.02.012.

Gorodnichenko, Y., and G. Roland. 2017. Culture, institutions, and the wealth of nations. Review of Economics and Statistics 99 (3): 402-416 doi.org/10.1162/REST_a_00599.

Gorodnichenko, Yuriy, and Gerard Roland. 2011. Which dimensions of culture matter for long-run growth? American Economic Review 101 (3): 492-498.

Granovetter, Mark. 2005. The impact of social structure on economic outcomes. Journal of Economic Perspectives 19 (1): $33-50$.

Grief, Avner. 2003. Comparative and historical institutional analysis: A game theoretic perspective. Cambridge: Cambridge University Press.

Gries, Thomas, and Wim Naudé. 2010. Entrepreneurship and structural economic transformation. Small Business Economics 34 (1): 13-29.

Harrison, Lawrence E. 2000. Culture matters. National Interest 60: 55-65.

Hofstede, Geert. 1980. Motivation, leadership, and organization: Do American theories apply abroad? Organizational Dynamics 9 (1): 42-63.

Hofstede, Geert. 1993. Cultural constraints in management theories. Academy of Management Executive 7 (1): 81-94.

Hofstede, Geert. 1994. The business of international business is culture. International Business Review 3 (1): 1-14.

Hofstede, Geert. 1999. Problems remain, but theories will change: The universal and the specific in 21st-century global management. Organizational Dynamics 28 (1): 34-44.

Hofstede, Geert. 2001. Culture's consequences: Comparing values, behaviors, institutions, and organizations across nations. 2nd ed. Thousand Oaks: Sage Publications. 
Hofstede, Geert, and Michael H. Bond. 1988. The Confucius connection: From cultural roots to economic growth. Organizational Dynamics 16 (4): 5-21.

Hofstede, Geert, Gert J. Hofstede, and Michael Minkov. 2010. Cultures and organizations: software of the mind. Revised and expanded. 3rd ed. New York City: McGraw-Hill.

Hofstede Insights. Country Comparison Tool. 2018. https://www.hofstede-insights.com/product/compare-countries/. Accessed 22 May 2018.

Human Development Data. 1997-2017. Human Development Index. http://hdr.undp.org/en/indicators/137506. Accessed 21 August 2018.

Huntington, Samuelson P. 1996. The clash of civilizations and the remaking of the world order. New York City, New York: Simon \& Schuster.

Jarque, C.M., and A.K. Bera. 1987. A test for normality of observations and regression residuals. International Statistical Review 55 (2): 163-172 doi.org/10.2307/1403192.

Jha, C., and B. Panda. 2017. Individualism and corruption: a cross-country analysis. Economic Papers 36 (1): 60-74 doi.org/10. 1111/1759-3441.12163.

Karras, Georgios. 1997. Economic integration and convergence: Lessons from Asia, Europe and Latin America. Journal of Economic Integration 12 (4): 419-432.

Klasing, M.J. 2013. Cultural dimensions, collective values and their importance for institutions. Journal of Comparative Economics 41 (2): 447-467 doi.org/10.1016/j.jce.2012.09.003

Korsgaard, S., and A.R. Anderson. 2011. Enacting entrepreneurship as social value creation. International Small Business Journal: Researching Entrepreneurship 29 (2): 135-151 doi.org/10.1177/0266242610391936.

Kuznets, Simon S. 1966. Modern economic growth: Rate, structure, and spread. New Haven: Yale University Press.

Kuznets, Simon S. 1973. Modern economic growth: Findings and reflection. American Economic Review 63 (3): 247-258.

Landes, David S. 1998. The wealth and poverty of nations: Why some are so rich and some so poor. New York City: W.W. Norton.

Landes, David S. 2003. The unbound Prometheus: Technological change and industrial development in Western Europe from 1750 to the present. 2nd ed. Cambridge: Cambridge University Press.

Lindberg, Leon N. 1963. The political dynamics of European economic integration. Palo Alto: Stanford University Press.

Liu, Xiaming, Haiyan Song, Yingqi Wei, and Peter Romilly. 1997. Country characteristics and foreign direct investment in China: A panel data analysis. Review of World Economics 133 (2): 313-329.

Mann, M., and D. Riley. 2007. Explaining macro-regional trends in global income inequalities, 1950-2000. Socio-Economic Review 5 (1): 81-115 doi.org/10.1093/ser/mwl017.

Mihet, Roxana. 2013. Effects of culture on firm risk-taking: A cross-country and cross-industry analysis. Journal of Cultural Economics 37 (1): 109-151.

Mokyr, J. 2005a. Chapter 17 - long-term economic growth and the history of technology. In Handbook of Economic Growth 1 (part B), 1113-1180 doi.org/10.1016/S1574-0684(05)01017-8.

Mokyr, J. 2005b. The intellectual origins of modern economic growth. Journal of Economic History 65 (2): 285-351 doi.org/10. $1017 / 50022050705000112$.

Mokyr, Joel. 1990. The lever of riches: Technological creativity and economic progress. Oxford: Oxford University Press.

Mokyr, Joel. 2002. The gifts of Athena: Historical origins of the knowledge economy. Princeton: Princeton University Press. National Geographic Society. 1999. National Geographic atlas of the world. 7th ed. Washington DC: National Geographic. North, D.C. 1991. Institutions. Journal of Economic Perspectives 5 (1): 97-112 doi.org/10.1257/jep.5.1.97.

North, D.C., and B.R. Weingast. 1989. Constitutions and commitment: The evolution of institutions governing public choice in seventeenth-century England. The Journal of Economic History 49 (4): 803-832 doi.org/10.1017/ S0022050700009451.

Rodrik, D. 2000. How far will international economic integration go? Journal of Economic Psychology 14 (1): 177-186 doi.org/ 10.1257/jep.14.1.177.

Rodrik, Dani. 2003. In search of prosperity: Analytic narratives on economic growth. Princeton: Princeton University Press.

Romer, Paul M. 1986. Increasing returns and long-run growth. Journal of Political Economy 94 (5): 1002-1037.

Romer, Paul M. 1990. Endogenous technological change. Journal of Political Economy 98 (5): S71-S102.

Santos-Álvarez, V., and T. García-Merino. 2010. The role of the entrepreneur in identifying international expansion as a strategic opportunity. International Journal of Information Management 30 (6): 512-520 doi.org/10.1016/j.jijnfomgt.2010. 03.008 .

Schumpeter, Joseph A. 1934. The theory of economic development: An inquiry into profits, capital, credit, interest, and the business cycle. Cambridge: Harvard University Press.

Schwarz, Gideon. 1978. Estimating the dimension of a model. Annals of Statistics 6 (2): 461-464.

Shane, S.A. 1992. Why do some societies invent more than others? Journal of Business Venturing 7 (1): 29-46 doi.org/10.1016/ 0883-9026(92)90033-N.

Snowdon, Brian, and Howard R. Vane. 2005. Modern macroeconomics: Its origins, development and current state. Cheltenham: Edward Elgar Publishing Limited.

Sorenson, Olav, and Pino G. Audia. 2000. The social structure of entrepreneurial activity: Geographic concentration of footwear production in the United States, 1940-1989. American Journal of Sociology 106 (2): 424-462.

Spolaore, E., and R. Wacziarg. 2013a. How deep are the roots of economic development? Journal of Economic Literature 51 (2): $325-369$ doi.org/10.2307/23644748

Spolaore, Enrico, and Romain Wacziarg. 2009. The diffusion of development. Quarterly Journal of Economics 124 (2): 469-529.

Spolaore, Enrico, and Romain Wacziarg. 2013b. Long-term barriers to economic development. 19361. Archive of National Bureau of economic research working papers. http://www.nber.org/papers/w19361. Accessed 16 October 2014.

Steenkamp, J.B.E.M., Ft Hofstede, and M. Wedel. 1999. A cross-national investigation into the individual and national cultural antecedents of consumer innovativeness. Journal of Marketing 63 (2): 55-69 doi.org/10.2307/1251945.

van Hoorn, A. 2014. Individualism and the cultural roots of management practices. Journal of Economic Behavior \& Organization 99: 53-68 doi.org/10.1016/j.jebo.2013.12.020. 
Williams, L.K., and S.J. McGuire. 2010. Economic creativity and innovation implementation: The entrepreneurial drivers of growth? Evidence from 63 countries. Small Business Economics 34 (4): 391-412 doi.org/10.2307/40650973.

Wooldridge, Jeffrey M. 2010. Econometric analysis of cross section and panel data. Cambridge: MIT press.

World Bank DataBank. World Development Indicators. https://databank.worldbank.org/data/source/world-developmentindicators. Accessed 18 August 2018.

Young, A. 1994. Lessons from the east Asian NICs: A contrarian view. European Economic Review 38 (3-4): 964-973 doi.org/10. 1016/0014-2921(94)90132-5.

Young, A. 1995. The tyranny of numbers: Confronting the statistical realities of the east Asian growth experience. Quarterly Journal of Economics 110 (3): 641-680 doi.org/10.2307/2946695.

Young, Alwyn. 1992. A tale of two cities: Factor accumulation and technical change in Hong Kong and Singapore. NBER Macroeconomics Annual 7: 13-54

Submit your manuscript to a SpringerOpen ${ }^{0}$ journal and benefit from:

- Convenient online submission

- Rigorous peer review

Open access: articles freely available online

High visibility within the field

Retaining the copyright to your article

Submit your next manuscript at $>$ springeropen.com 